\title{
Significado de espiritualidade e sua interface com a saúde: o Discurso do Sujeito Coletivo de pessoas idosas
}

\author{
Rogério Donizeti Reis*, José Vitor da Silva**
}

*Fisioterapeuta e Graduando em Enfermagem pela Escola de Enfermagem Wenceslau Braz, Itajubá, MG, **Orientador, Pósdoutorando pelo Programa de Pós-Graduação Stricto Sensu em Psicologia da Universidade São Francisco, Campus Itatiba, Itatiba/SP, professor titular da Universidade do Vale do Sapucai, Pouso Alegre/MG e da Escola de Enfermagem Wenceslau Braz, ItajubálMG

\section{Resumo}

Este estudo objetivou-se em conhecer os significados de espiritualidade emergentes de seres idosos e identificar a relação existente entre espiritualidade e a dimensão saúde sob a ótica de pessoas idosas. A abordagem foi qualitativa do tipo descritivo- exploratório e transversal. A amostra constituiu-se de 25 pessoas idosas, com 60 anos ou mais, do gênero masculino e feminino, residentes em Itajubá/MG. A amostragem foi intencional ou teórica. Os critérios de elegibilidade foram: estar residindo em Itajubá/MG; ter capacidade cognitiva e de comunicação preservadas e aceitar participar do estudo. Para a extração das ideias centrais e das expressôes chave, foram utilizadas as estratégias metodológicas do Discurso do Sujeito Coletivo. As ideias centrais emergentes do tema "Significados de espiritualidade" foram: "Diversos significados"; "Acreditar"; "Corpo e alma". Todos os participantes afirmaram que há relação entre espiritualidade e saúde. A relação entre espiritualidade e saúde foi representada por meio das seguintes expressôes: "A espiritualidade interfere na manutenção da saúde e na recuperação da doença"; "É a essência do ser humano"; "Há uma relação entre saúde e doença". Concluiu-se que os significados de espiritualidade foram de abrangência multidimensional e existe relação entre a espiritualidade e saúde. A dimensão espiritual interfere manutenção e recuperação da saúde.

Palavras-chave: idosos, espiritualidade, saúde, Enfermagem.

\section{Abstract}

The meaning of spirituality and the connection with health: collective subject discourse of elderly people

The purpose of this study was to know the meaning of emergent spirituality in the elderly and to identify the relationship between spirituality and health dimension from elderly people's point of view. This study has a qualitative approach with descriptive, transversal and exploratory design. The sample was composed of twenty-five participants aged 60 and older, both gender, residents of Itajubá/MG. The sampling was intentional or theoretical. The eligibility criteria were to be 
inhabitant of Itajubá/MG, to have cognitive ability and also communication ability preserved and to agree in participating in the study. We used methodological strategy of speech's collective subject in order to extract the main ideas and the key-words. The main emerging ideas about the subject matter "Meaning of spiritually" were "Several meanings", "Believe" and "Body and soul". All participants related that there is a relationship between spirituality and health, represented by the following expression "The spirituality interfere in maintenance of health and diseases recovery" "It's the human being's essence" "There is a relationship between health and disease". We conclude that the meaning of spirituality was multidimensional and that there is relationship between health and disease. The spiritual dimension interferes in maintenance of health and health recovery.

Key-words: seniors, spirituality, health, Nursing.

\section{Resumen}

\section{Significado de la espiritualidad y su relación con la salud: el discurso del sujeto colectivo de adultos mayores}

Este estudio tiene como objetivo conocer el significado de espiritualidad emergente de adultos mayores e identificar la relación entre la espiritualidad y la dimensión salud bajo la óptica de los adultos mayores. El abordaje fue cualitativo, del tipo exploratorio - descriptivo y transversal. La muestra consistió de 25 adultos mayores, con 60 años o más, hombres y mujeres, residentes en Itajubá/MG. El muestreo fue intencional o teórico. Los criterios de elegibilidad fueron: estar viviendo en Itajubá, MG; tener capacidad cognitiva y la comunicación conservadas y aceptar participar del estudio. Las estrategias metodológicas del Discurso del Sujeto Colectivo fueron utilizadas para sacar las ideas centrales y las expresiones clave. Las ideas del tema central "significados de espiritualidad" fueron: "Varios significados", "creer", "cuerpo y alma". Todos los participantes afirmaron que hay relación entre espiritualidad y salud. La relación entre espiritualidad y salud fue representada por las siguientes expresiones: "La espiritualidad interfiere en el mantenimiento y en la recuperación de la salud", "Es la esencia del ser humano", "Existe una relación entre la salud y la enfermedad." Se concluyó que los significados de la espiritualidad fueron de naturaleza multidimensional y hay una relación entre la espiritualidad y la salud. La dimensión espiritual interfiere en el mantenimiento y recuperación de la salud.

Palabras-clave: adultos mayores, espiritualidad, salud, Enfermería.

\section{Introdução}

A chegada de uma doença e a aproximaçáo da morte em pacientes gravemente enfermos faz com que a espiritualidade os torne mais ligados aos valores divinos, lhes dá uma visão menos narcísica e egoísta de si mesmos. Eles usam menos máscaras sociais, têm uma visão mais holística e compreensiva da realidade. Necessitam de Deus e da fé interiorizados. De um modo geral, vêem mais sentido na vida e podem aceitar e suportar as desilusóes, as dores e a própria morte. Portanto, nas horas de crise, nas doenças e no enfrentamento da morte, a espiritualidade tem sido realmente comprovada como uma dimensão de importância e significados vitais [1].

Especificamente, a enfermagem sempre teve na sua prática a preocupaçáo de assistir o paciente nas suas necessidades espirituais, porém tem tido dificuldade em diferenciar a espiritualidade dos aspectos religiosos e psicossociais do indivíduo [2].

Nosso interesse pelo tema espiritualidade e saúde surgiu a partir de nossa prática clínica (ensino clínico) com pessoas idosas internadas e gravemente enfermas.

Por outro lado, notamos ainda que, apesar da preocupação com a assistência espiritual dos pacientes, os profissionais e os acadêmicos de enfermagem sempre manifestavam a sua dificuldade de realizar esse tipo de assistência, alegando que desconheciam o que e como fazer e dizer. Sempre que tinham uma chance, transferiam essa responsabilidade aos demais colegas ou aos lideres religiosos.

A espiritualidade coloca questôes a respeito do significado da vida e da razão de viver, não se limitando a alguns tipos de crenças ou práticas [3]. A vivência espiritual comumente é uma experiência subjetiva, individual e particular. Algumas pessoas experienciam sua espiritualidade como um assunto altamente pessoal e privado, focalizando elementos intangíveis que os suprem de vitalidade e grande significado em suas vidas [4].

O desenvolvimento da espiritualidade consiste no cultivo da arte do contato sistemático com o eu profundo. Com isso, procura-se transformar 
a dimensão de transcendência, que faz parte da estrutura da vida, num elemento permanente de orientação da consciência e da ação e num projeto pessoal [5].

$\mathrm{Na}$ doença, a espiritualidade pode surgir como um recurso interno que favorece a sua aceitação, assim como o contato com as outras pessoas e o aproveitamento da ajuda dessas e até a própria reabilitação cura [6].

No envelhecimento, nas horas de crise, nas doenças e no enfrentamento da morte, a espiritualidade tem sido realmente comprovada como uma dimensão de importância e significados vitais [1].

A espiritualidade é um importante fator na vida dos idosos e que sua importância não diminui nos momentos de doença e da aproximação da morte. Eles esclarecem, ainda, que esse conceito pode ser um importante fator de exploraçáo do estado de saúde subjetivo de pessoas idosas [7].

Este estudo teve como objetivo conhecer os significados de espiritualidade emergentes de seres idosos e identificar a relação existente entre espiritualidade e a dimensão saúde sob a ótica de pessoas idosas.

\section{Material e métodos}

O presente estudo foi de abordagem qualitativa do tipo descritivo-exploratório e transversal. Os participantes deste estudo foram pessoas idosas, com 60 anos ou mais, de ambos os gêneros, residentes na cidade mineira de Itajubá. A amostra foi constituída por 25 pessoas idosas, de acordo com as características mencionadas anteriormente.

Os critérios de elegibilidade foram os seguintes:

- Estar residindo em Itajubá, MG.

- Ter capacidade cognitiva e de comunicação preservadas, avaliada pelo questionário de avaliação mental.

- Aceitar participar do estudo.

Os critérios de exclusão foram aqueles de natureza contrária aos critérios de elegibilidade.

Os dados foram colhidos nos domicílios das pessoas idosas ou em outros locais que elas considerarem adequados ou propícios à realizaçáo da entrevista.

A entrevista foi realizada após agendamento prévio com cada um dos participantes. Antes da realização da entrevista, o pesquisador explicou os objetivos do estudo, assim como o desenvolvimento de todo o trabalho e foram retiradas todas as dúvi- das. Foi obtida a anuência do entrevistado e, após seu consentimento, assinou o Termo de Consentimento Livre e Esclarecido. Antes da realização da entrevista, o entrevistador explicou sobre a entrevista gravada, tomando os devidos cuidados para que o participante náo se sentisse constrangido em relaçáo ao gravador. $\mathrm{O}$ ambiente foi isento de ruídos e proporcionando privacidade e segurança. Após a entrevista gravada, foi feita a sua transcrição e o material gravado contendo a fala dos participantes foi descartado.

Para a entrevista, utilizou-se roteiro de entrevista semiestruturada, sendo formada por duas perguntas abertas, que foram respondidas pelas pessoas idosas e que estão relacionadas com significados espiritualidade e sua relaçáo com a saúde.

A entrevista semiestruturada é aquela em que o pesquisador segue um roteiro previamente estabelecido; as perguntas feitas aos entrevistados são pré-determinadas. $\mathrm{O}$ motivo da padronização é obter dos entrevistados respostas às mesmas perguntas, permitindo que todas elas sejam comparadas com seu conjunto, e que diferenças devam ser refletidas entre os respondentes e as respostas [8].

$\mathrm{Na}$ estratégia de análise de dados foram obedecidas as diretrizes do DSC, foram adotadas neste estudo três figuras metodológicas: Expressóes-Chave, Ideia Central e Discurso do Sujeito Coletivo. Para o tratamento e análise dos dados, foi obedecida rigorosamente a ordem das seguintes etapas:

- 1a etapa: antes do início da transcrição dos dados, as respostas por escrito das questóes foram lidas várias vezes para que se tivesse uma ideia geral e melhor compreensão dos textos. Com os discursos escritos, foi feita a transcrição literal deles.

- 2a etapa: compreendeu uma cuidadosa leitura de todo o material transcrito, em dois momentos distintos: no primeiro, procedeu à leitura das respostas de cada um dos usuários, na sua totalidade. No segundo momento, cada resposta foi lida separadamente, ou seja, a questáo 1 de todos os respondentes, depois a questáo 2 , e finalmente, a terceira.

- $3^{\text {a }}$ etapa: consistiu na cópia integral de todas as respostas de cada respondente à questáo 1 no instrumento de Análise de Discurso 1 (IAD1), representando as $\mathrm{ECH}$ em itálico (Anexo B). De 
posse das ECH e após a leitura de cada uma, foi identificada a sua ideia central, tomando-se o cuidado de que a mesma represente a descrição das ECH e não a sua interpretação. Este mesmo procedimento foi realizado com as demais questóes.

- 4a etapa: elaboraçáo do Instrumento de Análise do Discurso 2 (IAD2), que contem separadamente, cada ideia central com as suas respectivas $\mathrm{ECH}$, semelhantes ou complementares (Anexo C).

- $5^{\mathbf{a}}$ etapa: Resume-se na extração do tema de cada uma das perguntas da entrevista semiestruturada, o conteúdo das IC, agrupando-se ao mesmo a sua respectiva IC, assim como os sujeitos, representados pelo número de entrevistados, e as frequências de ideias por meio de quadros. Por fim, foram constituídos os DSC separadamente de cada ideia central, com as suas respectivas $\mathrm{ECH}$.

O presente estudo obedece aos preceitos estabelecidos pela Resoluçáo no 196/96, de 16/10/96, do Ministério da Saúde, que trata da ética em pesquisa envolvendo seres humanos. São respeitados os aspectos éticos relacionados com anonimato total do entrevistado, sua privacidade e autonomia de aceitar ou não a participação no estudo. São considerados também do ponto de vista ético os valores culturais de cada participante. $\mathrm{O}$ informante teve o direito de se retirar do estudo se assim o desejasse e quando o desejasse, independentemente da fase que ele se encontrava. Antes da entrevista, ele teve ciência do Termo de Consentimento Livre e Esclarecido. O parecer consubstanciado que aprova a realizaçáo do estudo encontra-se sob o protocolo no 432/2011.

\section{Resultados}

O resultado apresentado refere ao tema explorado e seus respectivos discursos do sujeito coletivo.

Quadro 1 - Ideias centrais referentes ao tema "Significados de espiritualidade".

\begin{tabular}{|l|l|c|}
\hline \multicolumn{1}{|c|}{ Ideias centrais } & Participante do estudo & $\begin{array}{c}\text { Fre- } \\
\text { quência }\end{array}$ \\
\hline Diversos significados & $7,8,9,9,12,18,21,24$ & 8 \\
\hline Acreditar & $3,10,11,16.18$ & 5 \\
\hline Corpo e alma & $5,7,14,25$ & 4 \\
\hline
\end{tabular}

A seguir será apresentado o tema, sua respectiva ideia central e o discurso do sujeito coletivo correspondente às ideias de maior frequência:

\section{Significado de espiritualidade}

\section{Diversos significados}

- DSC: Espiritualidade é o elemento fundamental para o ser humano, ela nos leva a projetar na vida e nos dá energia que impulsiona a chamar e a aclamar a minha fé e a me interagir sempre com o nosso criador. Espiritualidade é uma experiência que a gente tem com a religião da gente, tendo na prática vertical Deus e horizonte o ser humano.

\section{Acreditar}

- DSC: Espiritualidade não é só matéria, mas parte do ser humano por inteiro. É a vivência da fé e do sacramento. É o que temos que acreditar sempre. É o que me impulsiona a chamar e aclamar a minha fé através da eucaristia, da obediência e fidelidade. Espiritualidade é o exercício contínuo de todas as minhas forças interiores, psíquicas e espirituais. E é nessa força que caminho por futuro alegre, feliz, acreditando sempre no ser superior e na salvação eterna.

\section{Corpo e alma}

- DSC: Espiritualidade não envolve religião, é uma qualidade mais ampla. É o que há de mais profundo em nós, é a aproximação da alma com Deus, é algo essencial na nossa vida, é a fusáo do corpo com o espírito, enfim, é essa dimensão espiritual que humaniza a nossa vida. Podemos desenvolver nossa espiritualidade com oraçóes, comunhão e meditaçáo e, assim, Deus nos inunda com seu amor, sua luz e seu perfume. Espiritualidade é uma mística, é uma força unificadora que facilita o nosso viver.

Quadro 2 - Ideias centrais referentes ao tema "Relação entre espiritualidade e saúde".

\begin{tabular}{|l|l|c|}
\hline \multicolumn{1}{|c|}{ Ideias centrais } & Participante do estudo & $\begin{array}{c}\text { Fre- } \\
\text { quência }\end{array}$ \\
\hline $\begin{array}{l}\text { A espiritualidade } \\
\text { interfere na manu- } \\
\text { tenção da saúde e } \\
\text { na recuperação da } \\
\text { doença. }\end{array}$ & $\begin{array}{l}1,3,4,6,8,10,11,12,13 \\
19,20,21,24,25\end{array}$ & 14 \\
\hline $\begin{array}{l}\text { É a essência do ser } \\
\text { humano. }\end{array}$ & $2,5,14,17,18,22,23$ & 7 \\
\hline $\begin{array}{l}\text { Há uma relação } \\
\text { entre espiritualidade } \\
\text { e saúde. }\end{array}$ & $7,9,15,16$ & 4 \\
\hline
\end{tabular}


A seguir será apresentado o tema, sua respectiva ideia central e o discurso do sujeito coletivo correspondente:

\section{Relação entre espiritualidade e saúde}

\section{Espiritualidade interfere na manutenção da saúde e na recuperação da doença}

- DSC: Com a força da mente é capaz de curar sérias enfermidades. Se tivermos a espiritualidade mais desenvolvida, acredito que será mais fácil vivenciar esse período triste que a pessoa está vivendo. Nós precisamos de espiritualidade sempre nos momentos de doença, pois, de acordo com estudos a pessoa enfrenta a doença com menos sentimentos de culpa, raiva, revolta, podendo ser curada pela fé. A espiritualidade pode influenciar no bem estar ou no mal estar do corpo. Nossa vida está baseada em transformaçóes e por que também não transformar nossa espiritualidade? Ela te proporciona equilíbrio, harmonia e prazer e isso nos fortalece e aumenta nossa resignaçáo em suportar a doença.

\section{Relação entre espiritualidade e saúde}

\section{É a essência do ser humano}

- DSC: A espiritualidade ajuda a aperfeiçoar o ser humano nas suas dimensóes físicas, sociais, racionais e afetivas. $\mathrm{Na}$ enfermidade, a espiritualidade serve como recurso interno que favorece a aceitação, a compreensão, a colaboraçáo e empenho na reabilitação. Acredito na relação da saúde e espiritualidade, pois ela é essencial para uma boa qualidade de vida e acredito também que a espiritualidade em relação à saúde é uma alavanca que impulsiona a nossa vontade de viver. Por isso, quando sofremos fisicamente náo podemos perder o sentido da vida, precisamos alimentar nosso espírito com muita oração e fé.

\section{Relaçáo entre espiritualidade e saúde}

\section{Há uma relação entre espiritualidade e saúde}

- DSC: Eu tenho convicção que é uma relação profunda entre espiritualidade e saúde. Se a pessoa vive uma espiritualidade elevada vai saber suportar as mazelas provocadas pelas nossas atitudes.
Muitas vezes, procuramos exaltarmos o nome de Deus quando estamos doentes, e se tivermos uma vida religiosa atuante acredito que possamos vivenciar cada segundo com total equilíbrio, esperança e otimismo. Olhando para a prática de Jesus, quando tudo era vida, a pessoa que procura viver o lado espiritual, a saúde se mantém, se preserva e até mesmo faz germinar a vida.

\section{Discussão}

A partir do século XX, o termo "espiritualidade" tem sido amplamente difundido para vários idiomas, relacionado ou não com tradiçôes religiosas e, apesar disso, ainda náo existe um conceito plenamente satisfatório e universal até os dias atuais [9]. A espiritualidade faz parte da natureza humana, devendo ser desvelada pela vivência e pelas descobertas individuais. A espiritualidade é diferente para cada indivíduo, podendo aparecer como propósito de vida, conexão com uma força/ um algo maior, autoconhecimento, entre outras formas [10]. A espiritualidade não é algo que ocorre para além da esfera humana, mas algo que toca em profundidade sua vida e experiência. A espiritualidade traduz a força de uma presença que escapa a percepçáo do humano, mas ao mesmo tempo provoca no sujeito o exercício de percorrer e captar esse sentido onipresente. Daí se pode falar em experiência espiritual enquanto movimento e busca do sentido radical que habita a realidade [11].

A espiritualidade poderia ser definida como uma propensão humana na busca do significado para a vida, por meios de conceitos que transcendem o tangível: um sentido de conexão com algo que é maior que si próprio, que pode ou náo incluir uma participação religiosa formal [12]. Ao analisar as narrativas referentes ao significado de espiritualidade emergiram várias ideias centrais como: "diversos significados", "acreditar", "corpo e alma”. A ideia que se sobressaiu foi "diversos significados", que de acordo com os participantes pode ser definida como: espiritualidade é uma experiência que a gente tem com a religiáo da gente, é a força que nos convida a viver de corpo e alma, cultivando assim a misericórdia, solidariedade, humanidade, bondade, compaixão, baseados nos ensinamentos bíblicos.

A espiritualidade se caracteriza por possuir elementos comuns a todas as religióes existentes tais como o amor, o respeito à vida, a fé a ética, a bondade, a igualdade e a liberdade [12]. É mencionado ainda que a espiritualidade é mais ampla e pessoal; está relacionada a um conjunto de valores íntimos, 
completude interior, harmonia, conexão com os outros; estimula um interesse pelos outros e por si; uma unidade com a vida, a natureza e o universo [13]. A ideia central "acreditar" após ser analisada, se evidenciou por meio do discurso que a espiritualidade não é só matéria, mas parte do ser humano por inteiro. É o que temos que acreditar sempre, é a vivência da fé e do sacramento, exercício contínuo de todas as minhas forças. Pode-se inferir no discurso anterior que a espiritualidade é a dimensão que caracteriza a integralidade do homem. Quando se fala em espiritualidade não se refere à visão parcial da pessoa por que ela é a força integradora que sela o homem um ser totalitário, contendo todas as dimensôes que as caracterizam como tal.

A espiritualidade pode ser definida também como dimensão que corresponde à abertura da consciência ao significado e à totalidade de vida, possibilitando uma recapitulaçáo qualitativa de seu processo vital. Portanto, envolve a busca pelo sentido ou significado para a existência e está articulada a uma necessidade mitificante, ao imaginário e ao simbólico [14].

A ideia central "corpo e alma", de acordo com os participantes relata que a espiritualidade não envolve religião, é a fusão do corpo com o espírito, podemos desenvolver nossa espiritualidade com orações, comunhão e meditação. Espiritualidade é uma mística, é uma força unificadora que facilita o nosso viver. A espiritualidade é traduzida como um modo de ser, uma atitude de base a ser vivida em cada momento e em todas as circunstâncias. Mesmo dentro das tarefas diárias da casa, trabalhando na fábrica, andando de carro, conversando com os amigos, vivendo a intimidade com a pessoa amada, a pessoa que criou espaço para a profundidade e para o espiritual está centrado, sereno e pervadido de paz. Irradia vitalidade e entusiasmo, porque carrega Deus dentro de si [15]. A espiritualidade pode ser definida também como uma força unificadora que não tem como propósito a vida de uma pessoa, mas facilitar seu desenvolvimento, dar uma orientação à realidade na vida diária e um significado para a sua existência, independente da sua profissáo religiosa [16].

Ao analisar as narrativas referentes à relação entre espiritualidade e saúde emergiram as seguintes ideias centrais: "a espiritualidade interfere na manutenção da saúde e na recuperação da doença”; “é a essência do ser humano"; "há uma relação entre saúde e espiritualidade".

A ideia central que sobressaiu foi "a espiritualidade interfere na manutenção da saúde e na recupe- ração da doença", que de acordo com os participantes pode ser comentada como: nós precisamos de espiritualidade sempre nos momentos de doença, pois, de acordo com estudos a pessoa enfrenta a doença com menos sentimentos de culpa, raiva, revolta, podendo ser curada pela fé. Nesse caso, a fé, tem que ser alimentada para nos tornarmos mais fortes e saudáveis. Nossa vida está baseada em transformaçóes e por que também não transformar nossa espiritualidade? Ela te proporciona equilíbrio, harmonia e prazer e isso nos fortalece e aumenta nossa resignação em suportar a doença. A religiosidade e a espiritualidade aparecem como importantes aliadas para as pessoas que se encontram enfermas. Contudo, são as consequências do enfrentamento religioso que prediráo se os resultados refletidos na saúde do paciente aparecem de forma positiva ou negativa [17].

O nosso estilo de vida é responsável pelo bom funcionamento de nosso organismo ou, seu estado de doença, isto é um bom começo. A idealização de hábitos transformadores e a busca do reconhecimento da importância do cultivo da espiritualidade podem iniciar o cultivo da prevenção através dos elementos que influenciam nosso comportamento e estilo de vida, no caso em questáo, a vida espiritual [18].

A ideia central "é a essência do ser humano" é evidenciado pelo discurso seguinte: A espiritualidade ajuda a aperfeiçoar o ser humano nas suas dimensóes físicas, sociais, racionais e afetivas. A enfermidade a espiritualidade serve como recurso interno que favorece a aceitaçáo, a compreensão, a colaboração e empenho na reabilitação.

A espiritualidade pode surgir, na doença, como um recurso interno que favorece a aceitaçáo da doença, o empenho no restabelecimento, a não evitação de sentimentos dolorosos, o contato e o aproveitamento da ajuda das outras pessoas e até a própria reabilitação [6].

A espiritualidade vista como essência do ser humano pode ser entendida como a parte mais profunda e indispensável do homem enquanto pessoa. A espiritualidade é aquela que faz o homem se distinguir dos demais animais e consequentemente ser diferente dele por que considera que existe um ser superior com o qual estabeleceu contatos, recebendo apoio e ajudas em todos os momentos da vida principalmente diante dos agravos da saúde. Isto faz com que o homem seja diferente de todos os demais seres, por que só ele possui essa essência, que se chama espiritualidade [5].

A ideia central "há uma relação entre saúde e doença” é definida pelos participantes como: eu tenho 
convicção que há uma relação profunda entre espiritualidade e saúde. Se a pessoa vive uma espiritualidade elevada vai saber suportar as mazelas provocadas pelas nossas atitudes. Se tivermos uma vida religiosa atuante acredito que possamos vivenciar cada segundo com total equilíbrio, esperança e otimismo.

A crença em aspectos espiritualistas é mais importante do que a comprovação com certeza da existência de tais conceitos. Tal crença pode mobilizar energias e iniciativas extremamente positivas, com potencial ilimitado para melhorar a qualidade de vida da pessoa, isso pode ter repercussóes tão significativas sobre o processo reabilitacional, que poderiam ser comparados a verdadeiros "milagres". A prece parece oferecer benefício subjetivo para aquele que ora [19].

Diante da doença, há nas pessoas enfermas a perda da integridade física, psicológica e emocional. O restabelecimento da integridade psicológica só será possível diante da cura das emoçóes e experiências negativas do passado, que se dá a partir da cura interior. $\mathrm{E}$ o restabelecimento da saúde física só se dará quando a cura psicoespiritual ou interior do enfermo for restabelecida [20].

\section{Conclusão}

De acordo com os objetivos propostos, os resultados do presente estudo permitiram as seguintes conclusóes:

Em relação ao significado de espiritualidade emanaram as seguintes ideias centrais: "relação com Deus e o outro"; "algo transcendental"; "corpo e alma"; "estudo que diverge corpo e espírito"; "cultivo do espírito"; "acreditar"; "algo essencial na vida"; "atividade espiritual"; "diversos significados". Diante da existência da relação entre espiritualidade e saúde todos os participantes disseram que há uma relação entre elas.

Sobre os comentários de relação entre espiritualidade e saúde sobressaíram às seguintes ideias centrais: "a espiritualidade interfere na manutenção da saúde e na recuperação da doença"; "é a essência do ser humano"; "há uma relação entre saúde e doença”.

A relação da espiritualidade com a saúde é cada vez mais evidenciada e reconhecida pelas pessoas idosas, considerando que no envelhecimento a espiritualidade é bastante acentuada entre elas. Diante disso cabe aos profissionais de saúde intervençóes junto aos idosos no que tange à assistência espiritual.

\section{Agradecimentos}

Pesquisa N. 432/2011 financiada pela Fundação de Amparo à Pesquisa do Estado de Minas Gerais (FAPEMIG).

\section{Referências}

1. Leloup JY. Cuidar do ser: Fílon e os terapeutas da Alexandria. Petrópolis: Vozes; 2002.

2. Atkinson LD, Murray ME. A necessidade de espiritualidade. In: Atkinson LD, Murray ME. Fundamentos de enfermagem. Rio de Janeiro: Guanabara Koogan; 1985. p. 566-72.

3. Fleck MPA, Borges ZN, Bolognesi G, Rocha NS. Desenvolvimento do WHOQOL, módulo espiritualidade, religiosidade e crenças pessoais. Rev Saúde Pública 2003;37(4):213-38.

4. Facure NO. Ciência e espiritualidade. Rev Filosofia 2003;6(6):353-6.

5. Boff F. Tempo de transcendência. Rio de Janeiro: Sextante; 2000.

6. Marques LF. A saúde e o bem-estar espiritual em adultos porto-alegrenses. Psicol Cienc Prof 2003;2(23):56-65.

7. Daaleman TP, Perera S, Studenski SA. Religión, spirituality, and health status in geriatric outpatients. Ann Fam Med 2004;2(1):49-53.

8. Lakatos EM, Marconi MA. Fundamentos de metodologia científica. 7a ed. Sáo Paulo: Atlas; 2010.

9. Gonçalves MAS, Pillon SC. Adaptação transcultural e avaliação da consistência interna da versão em português da Spirituality Self Rating Scale (SSRS). Rev Psiquiatr Clín 2009;36(1):10-5.

10. Dezorzi LW. Diálogos sobre espiritualidade no processo de cuidar de si e do outro para a enfermagem em terapia intensiva [dissertação]. Porto Alegre: Universidade Federal do Rio Grande do Sul; 2006.

11. Teixeira F. O potencial libertador da espiritualidade e da experiência religiosa. In: Amatuzzi MM, ed. Psicologia e espiritualidade. Sáo Paulo: Paulus; 2005. p. 13-30.

12. Santos NA, Guimarães DD. Espiritualidade, saúde e o cuidado de enfermagem. [monografia]. Espírito Santo: Faculdade Católica Salesiana do Espírito Santo; 2011.

13. Guerrero GP, Zago MMF, Sawada NO, Pinto MH. Relação entre espiritualidade e câncer: Perspectiva do paciente. Rev Bras Enferm 2001;64(1):53-9.

14. Monteiro DMR. Espiritualidade e saúde na sociedade do espetáculo. Mundo Saúde 2007;2(31):202-13.

15. Boff L. Espiritualidade, dimensão esquecida e necessária. [citado 2012 Dez 17]. Disponível em: URL: http://www.leonardoboff.com/site/vista/outros/espiritualidade.htm

16. Benko MA, Silva MJP. Pensando a espiritualidade no ensino de graduaçáo. Rev Latinoam Enferm 1996;4(1):71-85.

17. Fornazari AS, Ferreira RER. Religiosidade/espiritualidade em pacientes oncológicos: qualidade de vida. Psic Teor Pesq 2010;26(2):265-72.

18. Paula D. Espiritualidade: uma questão de saúde? Protestantismo em Revista 2012;27:17-24.

19. Saad M, Masiero D, Battistlla LR. Espiritualidade baseada em evidências. Acta Fisiátrica 2011;8(3):107-12.

20. Liessi ALM, Santos TR, Loures MC. Espiritualidade e a cura pela fé no cuidar. Estudos 2010;37(1/2):184-217. 